\title{
Non-surgical endodontic retreatment and follow-up of an endo - perio lesion: a case report
}

\author{
Toygan Bora \\ Toygan Bora, Private Clinic, Practice Limited To Endodontics, Istanbul, Turkey
}

Endo-perio lesion is a clinical dilemma and may be the most complex, refractory problem we encounter, even for the most experienced hands, and should not be underestimated. When a primarily endodontic pathology changes into a secondary periodontal lesion the clinical features become more unusual. This may delay the diagnosis and the correct treatment. This case report evaluates 6 months follow up of non surgical endodontic retreatment of an endo - perio lesion, which was treated before with conventional endodontic treatment and aims to show importance of obturation technique in lateral canals involved endo perio lesions.

Keywords: Endo-perio lesion; lateral canal; lateral condensation; warm vertical obturation.

$\mathrm{T}^{\mathrm{s}}$ The tooth, the pulp tissue it contains and its supporting structures should be viewed as one biologic unit. The interrelationship of these structures influences each other during health, function and disease. The relationship between the periodontium and the pulp was first discovered by Simring and Goldberg in 1964. ${ }^{[1]}$ The periodontium and pulp have embryonic, anatomic and functional interrelationship.

Endo- perio lesions primarily occur due to anatomic and vascular connections between pulp and periodontium. Pulp tissue degenerates due to a number reasons such as caries, restorative procedures, restorative materials, chemical insult, thermal insult, trauma and peridontal disease. Three main pathways have been implicated in the development of periodontal-endodontic lesions, namely: ${ }^{[2]}$

- Dentinal tubules

- Lateral and accessory canals

- Apical foramen
Pulpal and periodontal tissues are closely related and the disease transmission between these two lesions has been demonstrated by many studies, which showed significant microbiological similarities between infected root canals and advanced periodontitis. ${ }^{[3-6]}$

The possible pathways for ingress of bacteria and their products into these tissues can broadly be divided into: anatomical and nonphysiological pathways. ${ }^{[7]}$

The most important among the anatomical pathways are vascular pathways such as the apical foramen and the lateral canals and tubular pathways.

\section{Lateral canals}

In addition to the apical foramen which is the main avenue of communication, there are a multitude of branches connecting the main root canal system with the periodontal ligament and are now currently termed as 'accessory canals'. The term accessory canal is now used to describe

Correspondence: Dr. Toygan Bora. Sedef Caddesi, Mercan 6, Daire 5, 34758 Ataşehir, İstanbul, Turkey.

Tel: +90216-4555000 e-mail: toyganbora@gmail.com

Submitted: July 18, 2015 Accepted: July 16, 2015 
any ramification that connects the root canal system to the periodontal ligament. ${ }^{[7]}$

As the root develops, ectomesenchymal channels get incorporated, either due to dentine formation around existing blood vessels or breaks in the continuity of the Hertwig's root sheath, to become lateral or accessory canals.

The majority of the accessory canals are found in the apical part of the root and lateral canals in the molar furcation region. The frequency of these ramifications on the root surface are as follows: apical third $17 \%$, coronal third $1.6 \%$ and body of the root $8.8 \%{ }^{[8]}$ Bender et al., stated that periodontal endodontic problems were much more frequent in the molars than in the anterior teeth because of the greater number of accessory canals present in the molars. ${ }^{[9]}$ The percentage of lateral canals in the furcation is $46 \%$ in first molars ${ }^{[10]}$ and 50 to $60 \%$ in any multirooted teeth. ${ }^{[11]}$ Endo-perio lesions associated with lateral and accessory canals can successfully be treated with complete debridement and obturation of root canals. This case report describes the successful non-surgical management and follow-up of an endo-perio lesion.

It has been stated that lateral canals can radiographically be identified only if they are filled with a contrasting filling material. Radiographically the presence of lateral canals before obturation can be identified by the following:

\section{Case report}

A 42 year old female patient was referred to our clinic by a dentist. Her main complaint was the presence of mild pain during biting on her bridge on the left upper side. The patient had no medical history. Extraoral examination, revealed no contributory sign or swelling. In the intra oral examination the left second premolar was the most tender tooth during percussion test and there was a minor swelling associated with a sinus tract on the vestibular portion along the root surface. Sulcus depths around the tooth were within normal limits. Radiographic examination revealed that the left second premolar had an endodontic treatment before and had a lateral periapical lesion (Fig. la).

The patient's clinical and radiographic findings seemed to suggest a primary endodontic lesion associted with a secondary periodontal involvement. Two visit endodontic treatment was performed. Rubber dam was applied during both visits. At the first appointment, gutta percha in the root canal system was removed by ProTaper rotary retreatment files (Dentsply, Maillefer, Switzerland) and working

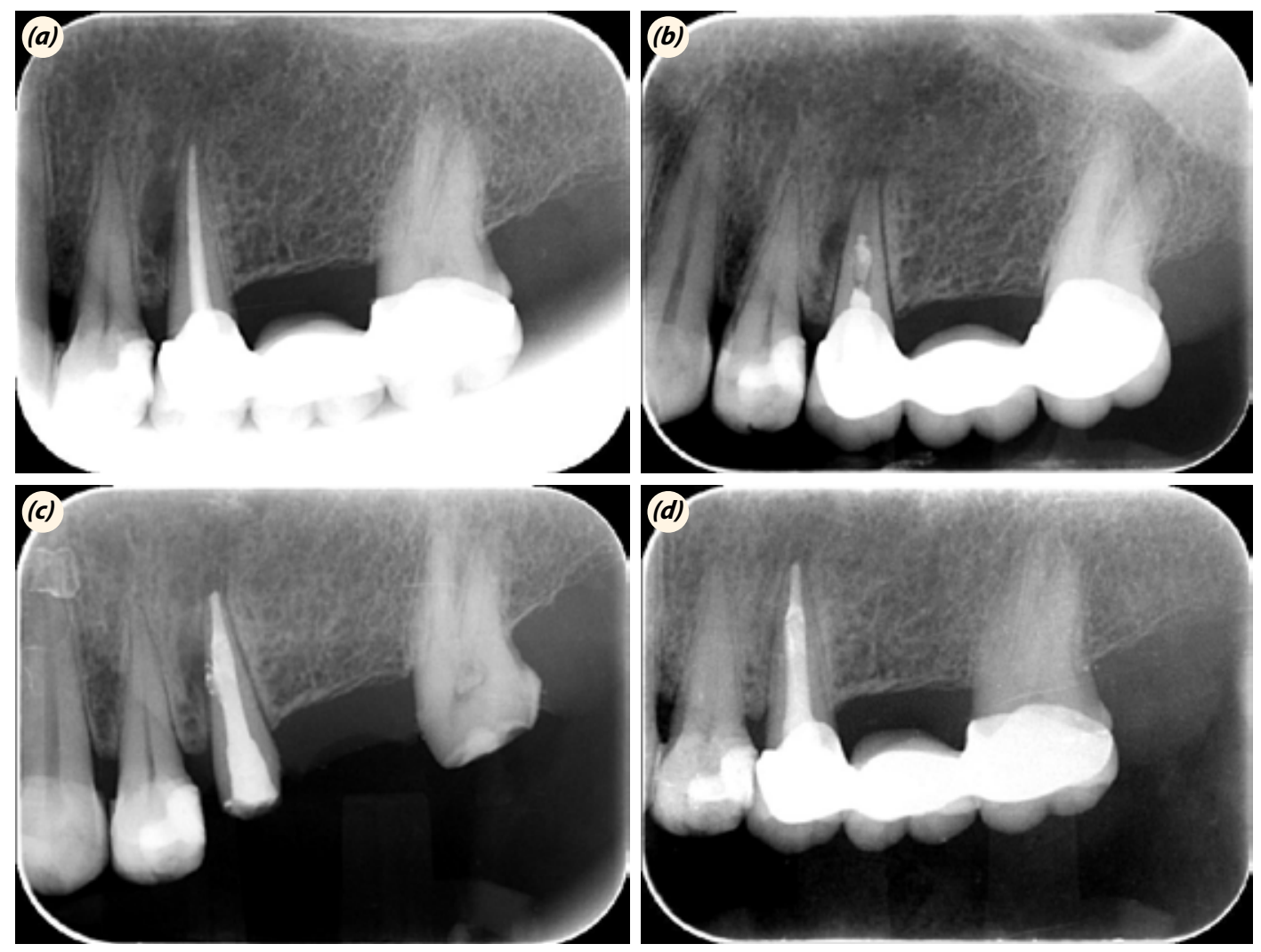

Fig. 1. (a) Periapical radiograph revealing a lateral periapical lesion. (b) Calcium hydroxide medication. (c) Root canal obturation. (d) Periapical radiograph taken 6 months later reveals healing of the lesion. 
length was determined by a \#45 $\mathrm{K}$ file radiographically. Root canal was shaped manually with $\mathrm{K}$ flexo reamers (Dentsply, Maillefer, Switzerland) till \#80 using step back technique and was irrigated with $\% 2.5$ sodium hypocloride with ultrasonic activation throughout the treatment. \%17 EDTA solution and \%2.5 NaOCl was used for final irrigation. Passive ultrasonic activation with Irrisafe tip (Acteon Satelec, Usa) for 1 minute was performed to activate $\mathrm{NaOCl}$. Calcium hydroxide was placed and patient was recalled for two weeks later (Fig. lb).

After two weeks of treatment sinus tract was healed, patient had no tenderness to percussion and symptoms disappeared. Root canal system was rinsed with EDTA to remove the calcium hydroxide (Ulracal XS, Ultradent) by help of ultrasonics (U Files, NSK). The root canal was irrigated with $2.5 \%$ sodium hypochlorite and saline solution. After drying the root canal obturation was performed by using warm vertical gutta percha technique and sealer (Kerr pulp canal sealer, Sybronendo, Usa) with downpack (System B Heat Source, Sybronedo, Usa) and backfill (Befill Backfill, Vdw Gmbh) systems. The access cavity was filled using a temporary filling material (Cavit, 3M ESPE, Germany) (Fig. lc) The patient was sent to the back to the referring dentist and a recall appointment was given six months later. During the follow-up, there was radiographical evidence of healing of the lesion and new bone formation (Fig. ld).

\section{Discussion}

Complex root canal anatomy may prevent satisfactory removal of bacteria and biofilm from root canal surfaces resulting in failure of endodontic treatment.

In this case, the canal was obturated by cold lateral condensation technique. Although it is one of the most common obturation techniques used by many colleagues, it might not be effective to obturate the irregularities in the root canal system.

Lateral compaction produces a cold-welded, non-uniform mass of gutta-percha cones in the coronal, middle, and apical portion of the canal without perfect replication of the canal, leaving space filled with sealer. ${ }^{[12]}$ Warm vertical compaction can increase the guta percha mass density and homogeniety. ${ }^{[13,14]}$ This technique has shown greater ability to flow into canal irregularities. ${ }^{[15-17]}$ A $10 \%$ higher healing rate was also reported with WVC versus CLC for teeth with previous apical periodontitis. ${ }^{[18]}$ It is also supported by studies that warm obturation techniques are significantlt better than cold lateral compaction in different ways. $^{[12-15]}$

In the root canal system was not curved so it was able to control the gutta parcha while condensing and visibility under microcope was better. However, negotiating curved root canals with pluggers and/or GP injection needles can be difficult. In such cases other warm gutta-percha techniques such as carrier based systems can be prefered to prevent voids inside the root canal. These systems have been shown to have gutta percha contents superior to system B and Cold lateral condensation techniques. ${ }^{[19,20]}$

Conflics of Interest: No conflicts declared.

\section{References}

1. Simring M, Goldberg M. The pulpal pocket approach: Retrograde periodontitis. J Periodontol.1964;35:22-48.

2. Rotstein I, Simon JH. Diagnosis, prognosis and decision making in the treatment of combined periodontal-endodontic lesions. Periodontol 2000 2004;34:265-303.

3. Tanner AC, Visconti RA, Holdeman LV, Sundqvist G, Socransky SS. Similarity of Wolinella recta strains isolated from periodontal pockets and root canals. J Endod 1982;8:294-300.

4. Kipioti A, Nakou M, Legakis N, Mitsis F. Microbiological findings of infected root canals and adjacent periodontal pockets in teeth with advanced periodontitis. Oral Surg Oral Med Oral Pathol 1984;58:213-20.

5. Kobayashi T, Hayashi A, Yoshikawa R, Okuda K, Hara $\mathrm{K}$. The microbial flora from root canals and periodontal pockets of non-vital teeth associated with advanced periodontitis. Int Endod J 1990;23:100-6.

6. Kerekes K, Olsen I. Similarities in the microfloras of root canals and deep periodontal pockets. Endod Dent Traumatol 1990;6:1-5.

7. Zehnder M, Gold SI, Hasselgren G. Pathologic interactions in pulpal and periodontal tissues. J Clin Periodontol 2002;29:663-71.

8. De Deus QD. Frequency, location, and direction of the lateral, secondary, and accessory canals. J Endod 1975;1:3616.

9. Bender IB, Seltzer S. The effect of periodontal disease on the pulp. Oral Surg Oral Med Oral Pathol 1972;33:45874.

10. Vertucci FJ, Williams RJ. Furcation canals in the human mandibular first molars. Oral Surg 1990;69:743.

11. Barkhordar RA, Stewart GG. The potential of periodontal pocket formation associated with untreated accessory root canals. Oral Surg Oral Med Oral Pathol 1990;70:769-72.

12. Blum JY, Michailesco P, Abadie MJ. An evaluation of the bactericidal effect of the Nd:YAP laser. J Endod 1997;23:583-5.

13. Nelson EA, Liewehr FR, West LA. Increased density of gutta-percha using a controlled heat instrument with lat- 
eral condensation. J Endod 2000;26:748-50.

14. Lea CS, Apicella MJ, Mines P, Yancich PP, Parker MH. Comparison of the obturation density of cold lateral compaction versus warm vertical compaction using the continuous wave of condensation technique. J Endod 2005;31:37-9.

15. Goldberg F, Artaza LP, De Silvio A. Effectiveness of different obturation techniques in the filling of simulated lateral canals. J Endod 2001;27:362-4.

16. Reader CM, Himel VT, Germain LP, Hoen MM. Effect of three obturation techniques on the filling of lateral canals and the main canal. J Endod 1993;19:404-8.

17. Clinton K, Van Himel T. Comparison of a warm gutta- percha obturation technique and lateral condensation. J Endod 2001;27:692-5.

18. Farzaneh M, Abitbol S, Lawrence HP, Friedman S; Toronto Study. Treatment outcome in endodontics-the Toronto Study. Phase II: initial treatment. J Endod 2004;30:302-9.

19. Gençoğlu N. Comparison of 6 different gutta-percha techniques (part II): Thermafil, JS Quick-Fill, Soft Core, Microseal, System B, and lateral condensation. Oral Surg Oral Med Oral Pathol Oral Radiol Endod 2003;96:91-5.

20. Gençoğlu N, Garip Y, Baş M, Samani S. Comparison of different gutta-percha root filling techniques: Thermafil, Quick-fill, System B, and lateral condensation. Oral Surg Oral Med Oral Pathol Oral Radiol Endod 2002;93:333-6. 